\title{
Feldspar minerals as efficient deposition ice nuclei
}

\author{
J. D. Yakobi-Hancock, L. A. Ladino, and J. P. D. Abbatt \\ Department of Chemistry, University of Toronto, Toronto, ON, Canada \\ Correspondence to: J. D. Yakobi-Hancock (jyakobi@chem.utoronto.ca)
}

Received: 24 May 2013 - Published in Atmos. Chem. Phys. Discuss.: 28 June 2013

Revised: 27 September 2013 - Accepted: 14 October 2013 - Published: 18 November 2013

\begin{abstract}
Mineral dusts are well known to be efficient ice nuclei, where the source of this efficiency has typically been attributed to the presence of clay minerals such as illite and kaolinite. However, the ice nucleating abilities of the more minor mineralogical components have not been as extensively examined. As a result, the deposition ice nucleation abilities of 24 atmospherically relevant mineral samples have been studied, using a continuous flow diffusion chamber at $-40.0 \pm 0.3{ }^{\circ} \mathrm{C}$ and particles size-selected at $200 \mathrm{~nm}$. By focussing on using the same experimental procedure for all experiments, a relative ranking of the ice nucleating abilities of the samples was achieved. In addition, the ice nucleation behaviour of the pure minerals is compared to that of complex mixtures, such as Arizona Test Dust (ATD) and Mojave Desert Dust (MDD), and to lead iodide, which has been previously proposed for cloud seeding. Lead iodide was the most efficient ice nucleus (IN), requiring a critical relative humidity with respect to ice $\left(\mathrm{RH}_{\mathrm{i}}\right)$ of $122.0 \pm 2.0 \%$ to activate $0.1 \%$ of the particles. MDD $\left(\mathrm{RH}_{\mathrm{i}} 126.3 \pm 3.4 \%\right)$ and ATD $\left(\mathrm{RH}_{\mathrm{i}} 129.5 \pm 5.1 \%\right)$ have lower but comparable activity. From a set of clay minerals (kaolinite, illite, montmorillonite), non-clay minerals (e.g. hematite, magnetite, calcite, cerussite, quartz), and feldspar minerals (orthoclase, plagioclase) present in the atmospheric dusts, it was found that the feldspar minerals (particularly orthoclase) and some clays (particularly kaolinite) were the most efficient ice nuclei. Orthoclase and plagioclase were found to have critical $\mathrm{RH}_{\mathrm{i}}$ values of $127.1 \pm 6.3 \%$ and $136.2 \pm 1.3 \%$, respectively. The presence of feldspars (specifically orthoclase) may play a significant role in the IN behaviour of mineral dusts despite their lower percentage in composition relative to clay minerals.
\end{abstract}

\section{Introduction}

Ice clouds affect the earth's energy budget and hydrological cycle, with their impact on climate representing one of the largest uncertainties in the forecasting of future climate (Baker and Peter, 2008; DeMott et al., 2010; Forster et al., 2007; Ramanathan et al., 2001). These clouds influence the radiative properties of the earth by trapping its outgoing infrared radiation and reflecting incoming visible solar radiation, thus having both a warming and cooling effect on the earth (Baker and Peter, 2008). The uncertainty in the impact of ice clouds on radiative forcing arises in part from an incomplete understanding of the formation processes of these clouds (Forster et al., 2007). Additionally, because a large portion of the total precipitation around the globe is initiated by ice formation within mixed phase clouds, the formation of glaciated clouds plays an important role in the exchange of water between the ocean and continents as well as between the planetary surface and the atmosphere (Lau and Wu, 2003; Lohmann and Diehl, 2006).

Ice crystals can form through both homogeneous and heterogeneous nucleation, with the former occurring at temperatures less than about $-38^{\circ} \mathrm{C}$ (Pruppacher and Klett, 1997). Heterogeneous ice nucleation occurs via atmospheric aerosols that facilitate the formation of ice crystals by lowering the free energy barrier of the nucleation event (Pruppacher and Klett, 1997). A variety of heterogeneous ice nucleation mechanisms has been identified (Vali, 1985): (i) deposition nucleation, where water vapour deposits directly onto a solid as ice; (ii) condensation freezing, which occurs when liquid water condenses on ice nuclei (IN) to form a liquid droplet at temperatures where it then rapidly freezes; (iii) immersion freezing, where an ice nucleus becomes immersed in a liquid droplet within which ice formation eventually occurs; and (iv) contact freezing, in which ice nuclei 
collide with supercooled liquid droplets to cause ice nucleation.

Mineral dusts and their main components (clay minerals including kaolinite and illite) are commonly acknowledged to be efficient ice nuclei that can facilitate the formation of high-altitude ice clouds (Hoose and Möhler, 2012; Pruppacher and Klett, 1997; Cziczo et al., 2013). The ice nucleation properties of these substances have been investigated through several methods including cloud chambers, cold stages, vacuum chambers, expansion chambers, continuous flow diffusion chambers, and the examination of snow crystal residues (e.g. Archuleta et al., 2005; Broadley et al., 2012; Kanji and Abbatt, 2006; Kumai, 1961; Möhler et al., 2006; Welti et al., 2009; Zuberi et al., 2002). Due to the use of widely differing experimental methods, previous studies have varied both in their sensitivity to nucleation events and in their experimental conditions. For instance, it has been established that the efficiency of a tested material can vary as a function of temperature, particle size, and the presence of soluble material that may be redistributed to enhance the hygroscopicity of insoluble particles (Fletcher, 1958; Koehler et al., 2007; Ladino and Abbatt, 2013; Lohmann and Diehl, 2006; Phebus et al., 2011; Wheeler and Bertram, 2012). In addition, the identification of an ice formation onset is highly dependent on the sensitivity of the observation technique, with some experiments (such as those conducted on cold stages) often sensitive to a single nucleation event out of a large surface area sample, whereas diffusion chambers are less sensitive, referring to the onset of a larger fraction of a smaller surface area sample. As a result of these experimental variations, it is challenging and indeed, at times, unhelpful to attempt to compare the IN efficiencies of substances from different studies.

While the IN properties of the main components of mineral dusts have been examined before, the IN activities of the more minor mineralogical components have not been extensively studied in a controlled manner, with the most recent being studies by Atkinson et al. (2013) and Zimmermann et al. (2008). Firstly, Atkinson et al. (2013) focussed on the immersion IN properties of feldspar minerals, and, secondly, Zimmermann et al. (2008) used environmental scanning electron microscopy to observe ice growth on a number of mineralogical components. In addition to clay minerals, mineral dusts from Asia, Africa, and Arizona can be composed of other minor minerals which include varying amounts of feldspars, quartz, hematite, and carbonates (e.g. Broadley et al., 2012; Jeong, 2008; Linke et al., 2006). Finally, Cziczo et al. (2013) identified metal-containing particles as another dominant component of the residual particles of cirrus ice crystals.

As a contrast to the naturally occurring minerals, an anthropogenic material, lead iodide $\left(\mathrm{PbI}_{2}\right)$, has been predicted to be an efficient ice nucleus based on the similarity of its crystal lattice to that of ice. Not only do both substances exhibit hexagonal lattice systems, but lead iodide was also found to possess lattice constants $(4.54 \AA, 8.86 \AA)$ that were nearly equal to those of ice along the $a$ axis (4.535 $\AA, 7.41$ A) (Barnes, 1929; Schaefer, 1954; Vonnegut, 1947). Due to this similarity, early studies were conducted in the immersion/condensation and deposition regimes (Baklanov et al., 1991; Harris et al., 1963; Morgan, 1967; Reischel, 1975; Schaefer, 1954), and it was proposed as a cloud seeding compound by Schaefer (1966), Morgan and Allee (1968), and Parungo and Rhea (1970). However, no studies using modern experimental techniques have been conducted on this compound.

The focus of this study is to use the same experimental approach to compare the relative ice deposition nucleating abilities of many minor mineralogical components of mineral dusts in addition to the major components. By controlling the particle size selection approach, temperature, particle preparation method, and the criterion for ice onset, we hope to identify in a relative sense the species that are most important in making mineral dust efficient deposition ice nuclei. In addition, the IN abilities of these substances are compared to that of lead iodide.

\section{Experimental procedure}

Experiments were conducted on particles size selected at $200 \mathrm{~nm}$ using the University of Toronto Continuous Flow Diffusion Chamber (UT-CFDC) at a temperature of $-40.0 \pm 0.3^{\circ} \mathrm{C}$, as illustrated in Fig. 1 (Kanji and Abbatt, 2009). Prior to experimentation, each compound was washed twice using Millipore water $(18.2 \mathrm{M} \Omega \mathrm{cm})$. A selection of compounds $\left(\mathrm{TiO}_{2}\right.$, orthoclase, Arizona Test Dust (ATD), Mojave Desert Dust (MDD)) was not washed prior to experimentation in order to compare the IN properties of the washed and unwashed forms of these samples. The purpose of the washing was twofold. Firstly, it allowed a relative ranking system of the IN properties of minerals to be created without interferences from soluble contaminants that may be present at the particles' surfaces. If such materials are present, either through handling, laboratory contamination, or from the manufacturer, then they may affect the underlying abilities of the pure compounds to nucleate ice. Secondly, it allowed the behaviour of these minerals to be compared to the multicomponent mixtures (ATD and MDD), which were washed as well, without interference from such material. We note that the washing procedure may also affect the surface composition of pure compounds; however, the research community is unclear about this. As well, the degree to which dust particles are "washed" in the environment is variable, depending on whether they undergo liquid water cloud processing or whether they experience rain when still on the ground.

Each compound was tested at least three times over the course of two or more days in order to ensure reproducibility. In the UT-CFDC, aerosol is continuously passed between 


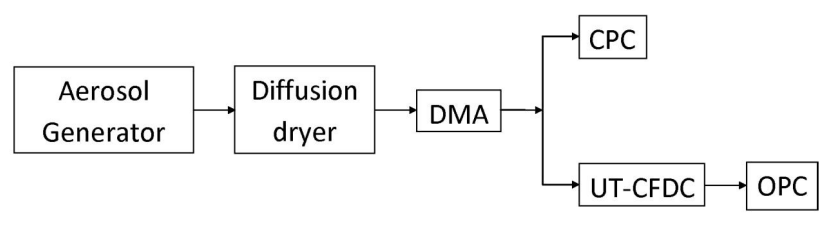

Fig. 1. Schematic of the main components of the experimental setup.

two horizontal, ice-coated copper plates that regulate the relative humidity $(\mathrm{RH})$ and temperature $(T)$ of the chamber; in particular, the different temperatures of the plates lead to a supersaturation with respect to ice in the centre of the chamber where the particle flow was injected $\left(0.3 \mathrm{~L} \mathrm{~min}^{-1}\right)$, in between a particle-free sheath flow $\left(2.6 \mathrm{~L} \mathrm{~min}^{-1}\right)$. After the UTCFDC, an optical particle counter (OPC, Climet CI-20) measured the number concentration of ice crystals greater than $5 \mu \mathrm{m}$ that exited the chamber. As particles larger than $5 \mu \mathrm{m}$ were not introduced into the UT-CFDC, these values were measurements of ice nuclei number concentrations, after low levels of background counts within the chamber were subtracted. By maximizing the residence time of particles within the chamber (12s), the degree to which ice nucleation may occur is also maximized. We refer the reader to Kanji and Abbatt (2009) for a full description of the UT-CFDC.

The total organic carbon level of the Millipore water used to wash the samples was extremely low (i.e. less than $5 \mathrm{ppb}$ ) as it was exposed to an ultraviolet light source for purification. In particular, the samples were washed with 500 to $1000 \mathrm{~mL}$ of water, the particles were allowed to settle, and then the supernatant liquid was poured off. This procedure was then repeated before addition of more water prior to atomization. To monitor the effectiveness of this procedure, the critical relative humidity with respect to ice $\left(\mathrm{RH}_{\mathrm{i}}\right)$ values of washed and unwashed $\mathrm{TiO}_{2}$, orthoclase, ATD, and MDD samples were compared by measuring the conductivity, and therefore the amount of soluble ionic material in each solution, using a conductivity meter (VWR 89094-958).

An aerosol generator (TSI 3076) was used to produce aerosol from a slurry, which was then dried with two silica gel drying tubes, size selected at a mobility diameter of $200 \mathrm{~nm}$ with a differential mobility analyzer (DMA, TSI 3081), and then passed into both a condensation particle counter (CPC, TSI 3010) for number concentration measurements, and the UT-CFDC. The slurries' concentrations were adjusted in order to produce number concentrations of 50200 particles $\mathrm{cm}^{-3}$ as measured by the CPC. Particle size selection was accomplished with the DMA at $200 \mathrm{~nm}$, with at most $25 \%$ of the total number of particles exiting the DMA being multiply charged particles larger than $200 \mathrm{~nm}$. For example, in the case of $\mathrm{Al}_{2} \mathrm{O}_{3}$, the fraction of particles that were multiply charged was only $7 \%$, whereas it was $25 \%$ for ATD. The percentage of total surface area that cannot be attributed to $200 \mathrm{~nm}$ particles was between $13 \%$ and
$60 \%$ for $\mathrm{Al}_{2} \mathrm{O}_{3}$ and $\mathrm{ATD}$, respectively. We note that the dry dispersal system available in our laboratory does not give clean monodispersed particle distributions when coupled to a DMA with a number of large particles being transmitted (see Ladino and Abbatt, 2013), whereas good size selection was always achieved with wet atomization. Since our primary goal is to establish a relative ranking of the IN abilities of these different species (i.e. free from the effects of particle size on the results), this was an additional reason for using wet atomization throughout.

All reported measurements are for a temperature of $-40.0 \pm 0.3^{\circ} \mathrm{C}$. To calculate the activated fraction $(\mathrm{AF})$, the number of ice crystals recorded by the OPC was normalized by the total number of injected aerosol particles counted by the CPC, after accounting for dilution by the CFDC sheath flow. The $\mathrm{RH}_{\mathrm{i}}$ was calculated using Eq. 1 based on Murphy and Koop (2005).

$\mathrm{RH}_{\mathrm{i}}=\frac{e}{e_{\mathrm{S}}(T)} \cdot 100 \%$,

where $e$ is the partial pressure of water vapour $(\mathrm{Pa})$ in the centre of the chamber and $e_{\mathrm{s}}$ is the saturated vapour pressure over ice. The critical $\mathrm{RH}_{\mathrm{i}}$ was defined in this work as the $\mathrm{RH}_{\mathrm{i}}$ at which $0.1 \%$ of the total number of injected aerosol particles had nucleated ice (i.e. formed $5 \mu \mathrm{m}$ crystals). The uncertainty in $\mathrm{RH}_{\mathrm{i}}$ is approximately $\pm 4 \%$ (Kanji and Abbatt, 2009).

The samples studied and their sources are listed in Table 1. The electrical conductivity $(\mu \mathrm{S})$ of the suspensions is indicated in parentheses for MDD, ATD, orthoclase, and $\mathrm{TiO}_{2}$ after the sample names. Most of the samples were obtained commercially with the exception of K-feldspar (herein referred to as orthoclase), $\mathrm{Ca} / \mathrm{Na}$-feldspar (herein referred to plagioclase), and calcium carbonate (herein referred to as calcite), which were obtained as individual mineral crystals from the Department of Earth Sciences, University of Toronto. These samples originated from the Bancroft area of Ontario, Canada, and were ground into sufficiently fine particles using a mortar and pestle.

\subsection{Mineral structures}

\subsubsection{Clay minerals}

Kaolinite is a $1: 1$ clay mineral in which one layer consists of an octahedral alumina sheet and a tetrahedral silica sheet that share a plane of oxygen atoms (Bear, 1964). The layers are held together by hydrogen bonds, and the surface consists of an alumina/hydroxyl sheet (Bear, 1964; Frost, 1998). As a result, the surface hydroxyl groups may be able to form hydrogen bonds with water molecules, thus causing kaolinite to be an efficient ice nucleus. Additionally, due to a low degree of isomorphic substitution of a fraction of the metal ions in the lattice by metals of lower charge, this clay carries a small net negative charge (1-10 mequiv/100 $\mathrm{g}$ of clay) which 
Table 1. Tested substances in order of increasing critical $\mathrm{RH}_{\mathrm{i}}$ for deposition activation of $0.1 \%$ of $200 \mathrm{~nm}$ particles at $-40{ }^{\circ} \mathrm{C}$. The electrical conductivity $(\mu \mathrm{S})$ of the suspensions is indicated in parentheses for MDD, ATD, orthoclase, and $\mathrm{TiO}_{2}$ after the sample names.

\begin{tabular}{|c|c|c|c|}
\hline Sample & Critical $\mathrm{RH}_{\mathrm{i}}(\%)$ & Category & Source \\
\hline $\mathrm{PbI}_{2}$ & $122.8 \pm 2.0$ & Anthropogenic & Sigma-Aldrich, $99 \%$ \\
\hline MDD unwashed $(70 \mu \mathrm{S})$ & $125.4 \pm 1.8$ & Mineral dust & Peters et al. (2008) \\
\hline $\operatorname{MDD}(50 \mu \mathrm{S})$ & $126.3 \pm 3.4$ & Mineral dust & Peters et al. (2008) \\
\hline Orthoclase (K-feldspar) $(18 \mu \mathrm{S})$ & $127.1 \pm 6.3$ & Feldspar mineral & Department of Earth Sciences, University of Toronto \\
\hline $\operatorname{ATD}(30 \mu \mathrm{S})$ & $129.5 \pm 5.1$ & Mineral dust & Powder Technology Inc., $0-5 \mu \mathrm{m}$ \\
\hline ATD unwashed $(89 \mu \mathrm{S})$ & $132.9 \pm 0.5$ & Mineral dust & Powder Technology Inc., $0-5 \mu \mathrm{m}$ \\
\hline Orthoclase (K-feldspar) unwashed $(50 \mu \mathrm{S})$ & $135.0 \pm 3.6$ & Feldspar mineral & Department of Earth Sciences, University of Toronto \\
\hline Plagioclase (Na/Ca-feldspar) & $136.2 \pm 1.3$ & Feldspar mineral & Department of Earth Sciences, University of Toronto \\
\hline Kaolinite & $136.4 \pm 1.9$ & Clay mineral & KGa-1b, Clay Minerals Society, Source Clays Repository \\
\hline Montmorillonite & $139.3 \pm 1.0$ & Clay mineral & K10, Sigma-Aldrich \\
\hline Illite & $142.5 \pm 2.3$ & Clay mineral & IMt-1, Clay Minerals Society, Source Clays Repository \\
\hline Pyrite (FeS) & $142.9 \pm 0.8$ & Metal sulfide & Sigma-Aldrich, technical grade \\
\hline Corundum $\left(\mathrm{Al}_{2} \mathrm{O}_{3}\right)$ & $143.2 \pm 3.2$ & Metal oxide & Sigma-Aldrich, $\geq 98 \%$ \\
\hline Calcite $\left(\mathrm{CaCO}_{3}\right)$ & $144.3 \pm 0.9$ & Metal carbonate & Department of Earth Sciences, University of Toronto \\
\hline Magnetite $\left(\mathrm{Fe}_{3} \mathrm{O}_{4}\right)$ & $144.4 \pm 2.2$ & Metal oxide & Sigma-Aldrich, $<5 \mu \mathrm{m}, 95 \%$ \\
\hline Quartz $\left(\mathrm{SiO}_{2}\right)$ & $144.7 \pm 1.5$ & Metal oxide & Alfa Aesar, $99.9 \%$ \\
\hline Gypsum $\left(\mathrm{CaSO}_{4} 2 \mathrm{H}_{2} \mathrm{O}\right)$ & $144.8 \pm 1.2$ & Metal sulfate & Sigma-Aldrich, $\geq 99 \%$ \\
\hline Galena (PbS) & $145.0 \pm 1.0$ & Metal sulfide & Sigma-Aldrich, $99.9 \%$ trace metal basis \\
\hline Anglesite $\left(\mathrm{PbSO}_{4}\right)$ & $145.1 \pm 1.3$ & Metal sulfate & Sigma-Aldrich, $98 \%$ \\
\hline $\mathrm{Zn}$ & $145.4 \pm 0.6$ & Pure metal & Atlantic Equipment Engineers, $99.8 \%$ \\
\hline Massicot $(\mathrm{PbO})$ & $145.5 \pm 1.3$ & Metal oxide & Sigma-Aldrich, $\geq 99.0 \%$ \\
\hline Calcite $\left(\mathrm{CaCO}_{3}\right)$ & $145.8 \pm 1.4$ & Metal carbonate & Sigma-Aldrich, $\geq 99.0 \%$ \\
\hline Rutile $\left(\mathrm{TiO}_{2}\right)$ unwashed $(10.8 \mu \mathrm{S})$ & $146.3 \pm 1.0$ & Metal oxide & Sigma-Aldrich, $99-100.5 \%$ \\
\hline Bunsenite $(\mathrm{NiO})$ & $146.5 \pm 0.8$ & Metal oxide & Sigma-Aldrich, $99 \%$ \\
\hline Cerussite $\left(\mathrm{PbCO}_{3}\right)$ & $146.7 \pm 0.6$ & Metal carbonate & Sigma-Aldrich, ACS reagent grade \\
\hline Rutile $\left(\mathrm{TiO}_{2}\right)(1.4 \mu \mathrm{S})$ & $147.4 \pm 0.4$ & Metal oxide & Sigma-Aldrich, $99-100.5 \%$ \\
\hline $\mathrm{ZnS}$ & $147.7 \pm 1.5$ & Metal sulfide & Sigma-Aldrich, $\geq 97.0 \%$ \\
\hline Zincite ( $\mathrm{ZnO})$ & $148.6 \pm 0.2$ & Metal oxide & Sigma-Aldrich, $\geq 99.0 \%$ \\
\hline Hematite $\left(\mathrm{Fe}_{2} \mathrm{O}_{3}\right)$ & $148.8 \pm 1.0$ & Metal oxide & Sigma-Aldrich, $<5 \mu \mathrm{m}, 99+\%$ \\
\hline
\end{tabular}

is compensated by the presence of counter cations (SwartzenAllen and Matijevic, 1974).

In contrast to kaolinite, illite is a $2: 1$ clay mineral possessing one octahedral alumina sheet between two tetrahedral silica sheets in each layer (Swartzen-Allen and Matijevic, 1974). Due to a high degree of isomorphic substitution, this clay carries a large net negative charge (80100 mequiv/ $100 \mathrm{~g}$ of clay) which is compensated by the presence of counter cations (Swartzen-Allen and Matijevic, 1974). The interlayer spaces are filled with counter cations, the majority of which are potassium ions (Hu et al., 2003). In addition to cations being present in the inter-layer space, they are also present at the clay's surface.

\subsubsection{Feldspar minerals}

Feldspars are a mineral class found commonly in igneous rocks, which make up a large fraction of the earth's crust (Carlson, 1920). Members of the feldspar mineral family consist of silica tetrahedra with varying degrees of Al-Si substitution, which results in surface charges and the presence of counterions within the crystal lattice (Papike and Cameron, 1976). While the counterion found in orthoclase is typically $\mathrm{K}^{+}$, those associated with the members of the plagioclase family are $\mathrm{Na}^{+}$and $\mathrm{Ca}^{2+}$ (Colville and Ribbe, 1968; Fitz Gerald et al., 1986; Phillips et al., 1971; Wenk et al., 1980).

\section{Results and discussion}

As examples, three activated fraction curves are shown in Fig. 2, plotted as a function of $\mathrm{RH}_{\mathrm{i}}$. It can be seen that more inactive species (e.g. $\mathrm{ZnS}$ ) have a better defined critical relative humidity which is close to water saturation, whereas the better IN (e.g. orthoclase and illite) have an activation spectrum spread across a wider range of $\mathrm{RH}_{\mathrm{i}}$, reflecting a range of active sites on the particles that have differing ice nucleating efficiencies. Note that the activation curves typically plateau at activated fractions close to 0.1 , which is a common occurrence in CFDCs. Incomplete activation of all particles is attributed to the depletion of water vapour within the chamber when many ice crystals have formed, as well as possibly to the depositional settling of ice crystals.

Indicated in Table 1 are the IN efficiencies of the tested samples, which fall into nine categories: anthropogenic substances, mineral dusts, feldspar minerals, clay minerals, metal carbonates, metal oxides, metal sulfates, metal sulfides, and pure metals. While the discussion will focus primarily on the mineral components of MDD and ATD, several other pure minerals are included in Table 1 to make a more complete comparison of minerals that may be present in other types of mineral dusts. In the following discussion Sects. 3.1 and 3.2 will focus on the relative IN properties of the washed samples, while Sect. 3.3 will compare the relative 


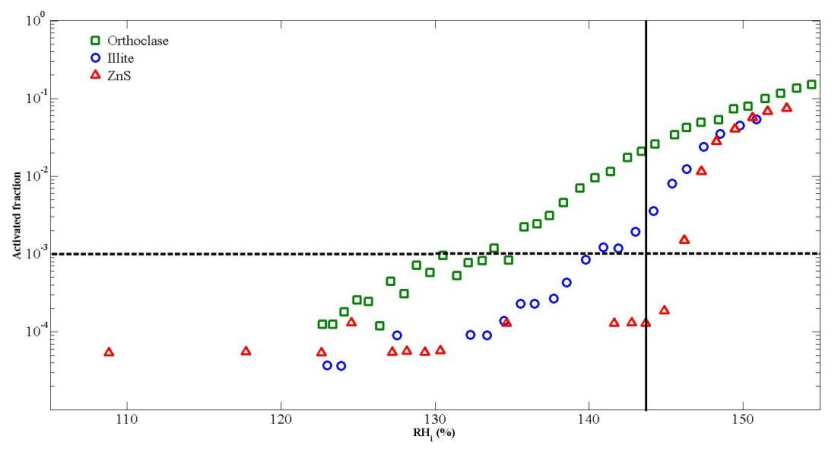

Fig. 2. Activated fraction as a function of $\mathrm{RH}_{\mathrm{i}}$ for orthoclase (green square), illite (blue circle), and $\mathrm{ZnS}$ (red triangle). The dashed black line represents an activated fraction of 0.001 , and the solid black line represents water saturation.

IN properties of a selection of washed and unwashed samples $\left(\mathrm{TiO}_{2}\right.$, orthoclase, ATD, MDD)

\subsection{IN properties of pure single component samples}

The most efficient classes of pure atmospheric substances were the clay and feldspar minerals, whereas the least efficient were metal oxides, carbonates, sulfates, sulfides, and the pure metal. Clay minerals including kaolinite and illite have been presented as the most important components of mineral dusts when considering their IN properties (Hoose and Möhler, 2012; Pruppacher and Klett, 1997). In accordance with this, the results of this study showed that these minerals were efficient IN relative to many of the other pure compounds that were investigated. Indeed, it is striking how many of the non-clays nucleate ice near water saturation (i.e. $146.2 \% \mathrm{RH}_{i}$ at $-40^{\circ} \mathrm{C}$ ). There is clearly a distinction to be made between the feldspars and clays, on the one hand, and the other compounds on the other hand.

\subsubsection{IN properties of clay minerals}

Kaolinite's critical $\mathrm{RH}_{\mathrm{i}}(136.4 \pm 1.9 \%)$ was greater than that reported by Salam et al. (2006), which was $118 \%$ at $-40^{\circ} \mathrm{C}$, where the critical $\mathrm{RH}_{i}$ was the value at which ice crystals were first detected. This low value may be attributed to the use of $1-2 \mu \mathrm{m}$ particles by Salam et al. (2006) because ice nucleation efficiency increases as a function of particle size (Archuleta et al., 2005; Kanji and Abbatt, 2006; Welti et al., 2009; Wheeler and Bertram, 2012). Welti et al. (2009) reported an onset $\mathrm{RH}_{\mathrm{i}}$ of $115 \%$ at $-40{ }^{\circ} \mathrm{C}$ when using $200 \mathrm{~nm}$ particles produced by a fluidized bed aerosol generator (i.e. generated in a different manner). An older study used a cold stage method to report that an $\mathrm{RH}_{\mathrm{i}}$ of $120 \%$ was necessary for a first ice nucleation event to occur at temperatures lower than $-1{ }^{\circ} \mathrm{C}$ (Roberts and Hallett, 1967). Similarly to Salam et al. (2006), the low $\mathrm{RH}_{\mathrm{i}}$ value may be attributed to the use of large kaolinite particles having diameters of $0.5-3 \mu \mathrm{m}$.
Due to illite's highly charged surface, this clay mineral may experience electrostatic interactions with the dipole moment of water, resulting in its fairly low critical $\mathrm{RH}_{\mathrm{i}}$ of $142.5 \pm 2.3 \%$. While this $\mathrm{RH}_{\mathrm{i}}$ is one of the lower values in Table 1, it is still much higher than the onset $\mathrm{RH}_{\mathrm{i}}$ of $110 \%$, which was reported by Welti et al. (2009) for $200 \mathrm{~nm}$ particles at $-40^{\circ} \mathrm{C}$; however, the studies differed with respect to the illite sources, ice crystal sizes for onset determination, and sample preparation methods. Welti et al. (2009) used an NX Nanopowder illite sample obtained from Arginotec, detected ice crystals described as being a few micrometres in size, and produced aerosol using a fluidized bed.

Due to the presence of counterions on the surfaces of clay minerals, there has been a significant amount of investigation regarding the effect of counterions on the adsorption of water by clays. It has been reported that clays possessing polyvalent counterions adsorb more water vapour than those having univalent counterions (Swartzen-Allen and Matijevic, 1974). Therefore, it may be hypothesized that the kaolinite sample possessed more highly charged counterions than the illite samples. In addition, both the charge and ionic size of counterions have been reported to influence the strength of their interactions with clay surfaces (Swartzen-Allen and Matijevic, 1974). As a result, the degree of preferential $\mathrm{H}^{+}$ adsorption to clay surfaces has been investigated. However, this work has been inconclusive as various studies have found different preferences for $\mathrm{H}^{+}$adsorption (Swartzen-Allen and Matijevic, 1974). Because of the limitations of this study and the inconclusiveness of past work, we can only make a general conclusion that the electrostatic interactions between the charged clay surfaces, counterions, and the dipole moment of water may be influencing the IN properties of clays.

\subsubsection{IN properties of feldspar minerals}

While the clay minerals were identified as efficient IN as predicted, the surprising results are the very high efficiencies of the feldspars. It has been reported that the outermost $\mathrm{K}^{+}$ ions of orthoclase are removed upon contact with deionized water, and dangling $\mathrm{Si}$ atoms become attached to $\mathrm{O}$ or $\mathrm{OH}$ (Fenter et al., 2000). As a result, the surface would be prone to interact with water molecules through hydrogen bonding, as is the case for kaolinite, which was the more active clay mineral (critical $\mathrm{RH}_{\mathrm{i}} 136.4 \pm 1.9 \%$ ). Incidentally, the critical $\mathrm{RH}_{\mathrm{i}}$ values of orthoclase and kaolinite were not significantly different according to Student's $t$ test, which is used to determine whether two data sets significantly differ from one another.

In addition, as plagioclase minerals have a similar crystal structure to orthoclase, it may be that they also have the ability to form hydrogen bonds with water molecules. Therefore, it was not surprising that the critical $\mathrm{RH}_{\mathrm{i}}$ values of plagioclase and kaolinite were also not significantly different according to Student's $t$ test. This implies that their interaction with water molecules may be similar. Additionally, the 
charged crystal lattice of feldspars may also allow electrostatic interactions to occur between their surfaces and the dipole moment of water, as is the case for illite. The differing activities of the two feldspar samples may be due to different degrees of hydrogen bonding and electrostatic interactions that are exhibited by each sample.

In contrast with the clay minerals, the feldspar mineral class has been poorly studied by the ice nucleation community, with reports being for feldspar-containing soil and illite samples, as well as for pure feldspar samples, that acted as IN in the deposition, contact, and immersion modes (Broadley et al., 2012; Roberts and Hallett, 1967; Rosinski and Nagamoto, 1976a, b; Rosinski et al., 1971, 1974; Zimmermann et al., 2008). Additionally, older reports have investigated the IN properties of pure feldspar samples in unknown modes (Isono and Ikebe, 1960; Mason and Maybank, 1958). In one study a cold chamber was used to report that $72.4 \%$ of 40 $60 \mu \mathrm{m}$ soil particles containing $5 \%$ feldspar nucleate ice in the immersion mode at temperatures below $-20^{\circ} \mathrm{C}$ (Rosinski and Nagamoto, 1976b). In a second paper it was reported, using the same instrument and soil samples, that about $40 \%$ of one of the samples having diameters of 5-20 $\mu \mathrm{m}$ functioned as IN in the contact mode at about $-16^{\circ} \mathrm{C}$ (Rosinski and Nagamoto, 1976a). More recently, a study by Broadley et al. (2012) examined the IN activity of illite-rich powder (NX illite), containing about $8 \%$ feldspar, using a cold stage. Immersion freezing was found to occur primarily below the median freezing temperature of $-27^{\circ} \mathrm{C}$. While all three of these studies identified the feldspar-containing particles as being fairly efficient IN in various modes, none of them identified the feldspar component as the source of the IN activities. In addition, because the methods, soil particle sizes, definition of activity, IN modes, and feldspar-containing samples themselves differed from those used in this study, a comparison with this past work is very challenging. In addition, Zimmermann et al. (2008) investigated the IN properties of two types of feldspars (albite and microcline) in the deposition mode with the use of a cold stage. At $-25^{\circ} \mathrm{C}, 1-10 \mu \mathrm{m}$ albite and microcline particles were found to nucleate ice at critical $\mathrm{RH}_{\mathrm{i}}$ values of about $114 \%$ and $118 \%$, respectively. Critical $\mathrm{RH}_{\mathrm{i}}$ values corresponded to 1-3\% activation. The difference between these critical $\mathrm{RH}_{\mathrm{i}}$ values and those reported here is to be expected because of the difference in experimental conditions. However, it should be noted that of the nine minerals examined by Zimmermann et al. (2008), the feldspars were found to be among the more active minerals, which supports the conclusions of this study. Most recently, a concurrent study by Atkinson et al. (2013) found that while clay minerals dominate the composition of mineral dusts, it is the feldspar minerals that dominate their immersion IN properties. This work is very much in agreement with our conclusions, with respect to the excellent deposition IN abilities of feldspars.

\subsubsection{IN properties of other pure compounds}

In contrast with the more structurally complex minerals having ionic surfaces, other minerals found in mineral dusts have lower capacities to interact with water molecules through electrostatic and hydrogen bonding interactions. In particular, of the minerals present in MDD and ATD, hematite and cerussite were found to be the least efficient minerals as they were activated above water saturation. Similarly, magnetite, calcite, and quartz were very poor ice nuclei in the deposition regime. These results are somewhat surprising, as Cziczo et al. (2013) found that in addition to mineral dust, metallic particles are a dominant component of ice crystal residuals in cirrus clouds.

In general, species such as magnetite $\left(\mathrm{Fe}_{3} \mathrm{O}_{4}\right)$, hematite $\left(\mathrm{Fe}_{2} \mathrm{O}_{3}\right)$, and quartz $\left(\mathrm{SiO}_{2}\right)$ are stable oxides that will either have metal-O bonds at their surfaces, or perhaps some metal$\mathrm{OH}$ groups; for example, alumina is known to have hydroxyl functional groups present under some conditions (SwartzenAllen and Matijevic, 1974). Similarly, hydroxyl groups may be present at the surface of quartz, which would allow hydrogen bonding to occur between quartz and water molecules (Schlegel et al., 2002, and references therein). However, its poor IN activity may be attributed to its lack of structural charge. To compare, orthoclase has hydrogen bonding abilities due to the presence of surface $\mathrm{Si}-\mathrm{OH}$ groups; however, this is due to the removal of potassium ions from its surface (Fenter et al., 2000). This also results in the exchange of potassium ions with protons or hydronium ions upon exposure to water (Fenter et al., 2000, and references therein). Therefore, the IN properties of orthoclase may be due to the presence of a surface charge and ions, as well as to its hydrogen bonding abilities.

Lastly, as expected based on the similarities between the crystal structures of lead iodide and ice, lead iodide was reported to be the most efficient ice nucleus of those considered here (critical $\mathrm{RH}_{\mathrm{i}}$ of $122.8 \pm 2.0 \%$ ). Harris et al. (1963) observed a deposition onset $\mathrm{RH}_{\mathrm{i}}$ of approximately $143 \%$ at $-35^{\circ} \mathrm{C}$ when using a cold chamber, where the onset $\mathrm{RH}_{\mathrm{i}}$ was defined as the first observed nucleation event. The particle size used in this study was $0.1-2 \mathrm{~mm}$, and nucleation events were recorded by eye with the use of a Vickers projection microscope, which may have caused some of the very early nucleation events to be overlooked. Baklanov et al. (1991) reported that $3 \times 10^{16}$ ice crystals per $\mathrm{kg}$ of $\mathrm{PbI}_{2}$ formed when $40-100 \mathrm{~nm} \mathrm{PbI}_{2}$ particles were injected into an isothermal cloud chamber at $-10^{\circ} \mathrm{C}$.

\subsection{IN properties of mineral dusts}

Figure 3a shows the critical $\mathrm{RH}_{\mathrm{i}}$ at which $0.1 \%$ of the ATD and Mojave Desert Dust (referred to as Mojave Mars Simulant, or MMS in previous studies) particles activated at a temperature of $-40.0 \pm 0.3^{\circ} \mathrm{C}$. For reference, the results for lead iodide are also shown. 


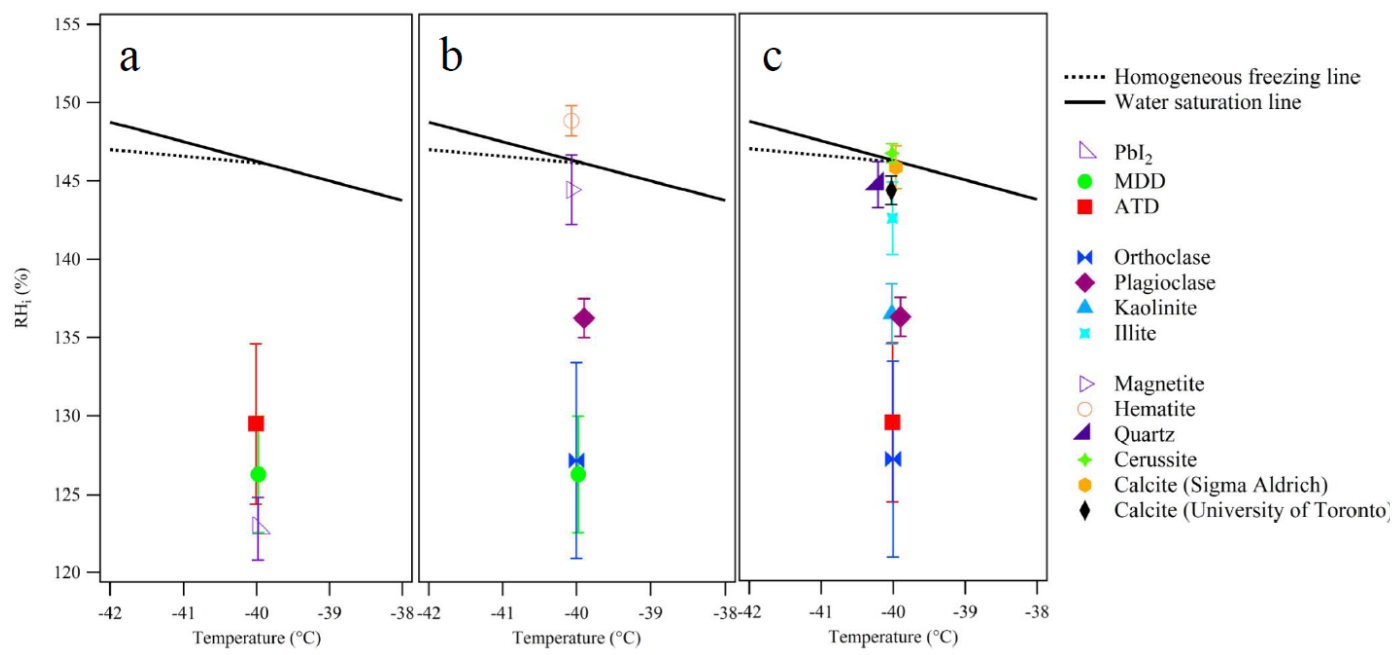

Fig. 3. Critical $\mathrm{RH}_{\mathrm{i}}$ at which $0.1 \%$ of particles were activated at a temperature of $-40.0 \pm 0.3{ }^{\circ} \mathrm{C}$. The solid black line represents the water saturation line and the dotted black line represents the homogeneous freezing line (Koop et al., 2000; Murphy and Koop, 2005). The three panels are as follows: (a) ATD, MDD, and $\mathrm{PbI}_{2}$; (b) MDD and its mineral components (orthoclase, plagioclase, magnetite, hematite); (c) ATD and its mineral components (orthoclase, plagioclase, kaolinite, illite, quartz, and carbonates such as calcite and cerussite). The error bars represent the standard deviation of the critical $\mathrm{RH}_{\mathrm{i}}$ measured in individual experiments, of which each point is the average of at least three scans.

Mojave Desert Dust is very efficient with a critical $\mathrm{RH}_{\mathrm{i}}$ of $126.3 \pm 3.4 \%$. It is striking that the IN efficiency of this natural dust is nearly comparable to that of an artificial IN, such as lead iodide which was identified for its very close crystal match to that of ice. The value for MDD is in agreement with the previously reported value of $\mathrm{RH}_{\mathrm{i}}=123 \%$ from our group at a temperature of $-53^{\circ} \mathrm{C}$ and particle diameter of $240 \mathrm{~nm}$ (Ladino and Abbatt, 2013). Motivated by ice cloud nucleation on Mars, this past study also indicated that there is a strong temperature dependence on this onset value, with it rising substantially at temperatures lower than $-50^{\circ} \mathrm{C}$ (Ladino and Abbatt, 2013).

Arizona Test Dust was found to be less efficient as an ice nucleus (critical $\mathrm{RH}_{\mathrm{i}} 129.5 \pm 5.1 \%$ ) under the investigated conditions. As ATD is a standard sample in the ice nucleation community, several studies have been conducted to investigate its activity using a CFDC (Archuleta et al., 2005; Koehler et al., 2010; Welti et al., 2009). Welti et al. (2009) and Koehler et al. (2010) reported critical $\mathrm{RH}_{\mathrm{i}}$ values of about $118 \%$ and $128 \%$, respectively, where these values corresponded to the activation of $1.0 \%$ of ATD particles at $-40^{\circ} \mathrm{C}$ and $200 \mathrm{~nm}$ in size. These values were not in agreement with each other; however, the value reported by Koehler et al. (2010) agreed well with the value from this study. The disagreement with Welti et al. (2009) may be attributed to their detected ice crystal sizes, which were described as being a few microns. Because the ice crystals detected in this study were relatively large $(5 \mu \mathrm{m})$, a higher $\mathrm{RH}_{\mathrm{i}}$ would be required for their formation. This divergence in the literature results for not only ATD, but many other substances as well, emphasizes the need for this study that uses the same experimental protocol for all samples, in order that the relative nucleating abilities of these materials be established.

ATD has been reported to contain about $30 \%$ feldspar minerals (e.g. plagioclase, orthoclase), and more minor amounts of kaolinite, illite, illite-smectite, quartz, carbonates (e.g. calcite, cerussite) and other unidentified clay minerals, in varying amounts (Broadley et al., 2012). On the other hand, MDD consists of mainly feldspars, hematite, and minor amounts of magnetite, without the same contributions of clay minerals or carbonates as in ATD (Peters et al., 2008). Indeed, it is due to its more igneous nature and relative lack of weathered and sedimentary components, such as clays and carbonates, that it has been used as a simulant for Mars dust.

Because these mineral dusts consist of several pure minerals, it is reasonable to hypothesize that the overall IN ability of the dusts may be understandable in terms of the IN activities of their individual components. Figure $3 \mathrm{~b}$ shows the critical $\mathrm{RH}_{\mathrm{i}}$ at which $0.1 \%$ of aerosol particles of MDD and its main mineralogical components (hematite, magnetite, feldspar) were activated. As the $\mathrm{RH}_{\mathrm{i}}$ values of hematite and magnetite were $148.8 \pm 1.0 \%$ and $144.4 \pm 2.2 \%$, respectively, they are unlikely to contribute to the IN abilities of MDD. Rather, the most efficient components of MDD were the feldspar minerals orthoclase and plagioclase, supporting the hypothesis that the feldspars (specifically orthoclase) are likely contributors to the IN properties of the mineral dusts. Of course, we cannot rule out that the mixing of these constituents to form an MDD particle (i.e. its specific morphology) may also result in the formation of active sites or 


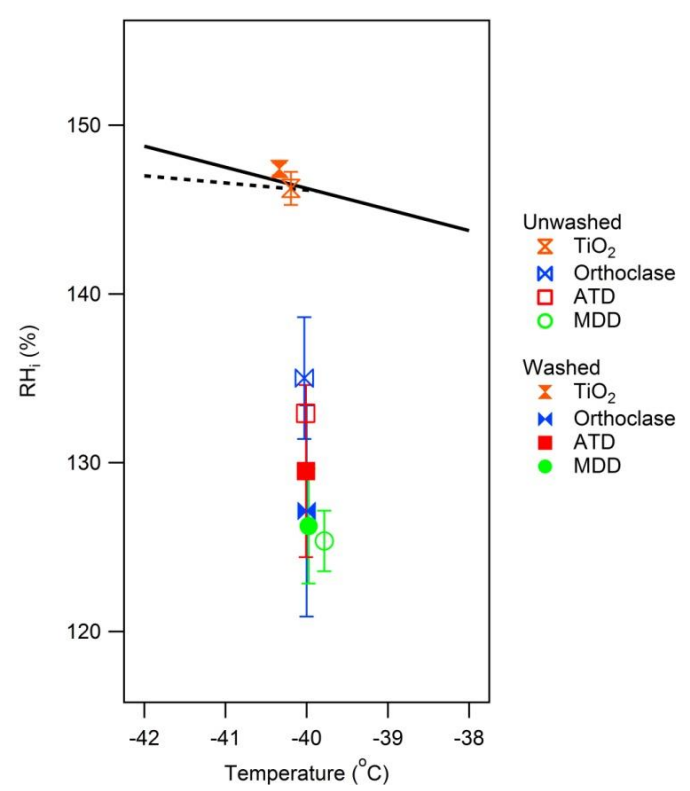

Fig. 4. Critical $\mathrm{RH}_{\mathrm{i}}$ at which $0.1 \%$ of particles were activated at a temperature of $-40.0 \pm 0.3^{\circ} \mathrm{C}$. The solid black line represents the water saturation line, and the dotted black line represents the homogeneous freezing line (Koop et al., 2000; Murphy and Koop, 2005). The solid markers indicate washed samples while the empty markers indicate unwashed samples of $\mathrm{TiO}_{2}$, orthoclase, ATD, and MDD. The error bars represent the standard deviation of the critical $\mathrm{RH}_{\mathrm{i}}$, each of which is the average of at least three scans.

physical imperfections that facilitate ice formation (Pruppacher and Klett, 1997).

Figure $3 \mathrm{c}$ shows the critical $\mathrm{RH}_{\mathrm{i}}$ at which $0.1 \%$ of aerosol particles of ATD and its main mineralogical components were activated at a temperature of $-40.0 \pm 0.3^{\circ} \mathrm{C}$. Once again, the minerals having more complex crystal structures (kaolinite, plagioclase, and orthoclase) were found to be more efficient deposition ice nuclei. The similarity of the orthoclase and ATD activities suggests that the efficiency of ATD may also be primarily explained by the presence of orthoclase despite the large fraction of clays in ATD (Broadley et al., 2012). As MDD was found to activate at very low $\mathrm{RH}_{\mathrm{i}}$ values more consistently than ATD, it may be that MDD particles contain orthoclase more consistently than do ATD particles.

\subsection{Unwashed and washed samples}

As described above, washing was performed to remove soluble impurities that might affect our ability to rank the different species by their IN ability. An attempt was made to assess the effects of washing the samples prior to studying their IN properties. Shown in Fig. 4 are the critical $\mathrm{RH}_{\mathrm{i}}$ values of washed and unwashed $\mathrm{TiO}_{2}$, orthoclase, ATD, and MDD samples. According to Student's $t$ test, the $\mathrm{RH}_{\mathrm{i}}$ values of the washed and unwashed samples for each of the four ma- terials considered were not significantly different from one another. Therefore, we conclude that washing does not alter the general conclusions about whether a particle is a good IN or not. These effects may be due to the removal of soluble material that would otherwise affect their IN properties, either by promoting ice nucleation through additional electrostatic interactions or inhibiting it by blocking active sites. In contrast with orthoclase, ATD, and $\mathrm{MDD}, \mathrm{TiO}_{2}$ is an example of a synthetically manufactured pure chemical compound having greater than $99 \%$ purity. Consequently, a relatively small amount of soluble material was present regardless of the number of washings. Indeed, based on the electrical conductivity measurements (see Table 1) of the supernatant water after washing, we estimate that there are fewer than $5 \times 10^{3}$ soluble ions per particle present. To do this calculation, we use the measured conductivity of the atomizer slurry $(1.4 \mu \mathrm{S})$ to estimate its ion content, assuming the constituents are $\mathrm{NaCl}$, and then calculated the number of ions in each atomized droplet, assuming these to be $1.2 \mu \mathrm{m}$ in size. Upon drying, these ions then will become part of the dried $200 \mathrm{~nm}$ particle. It is not surprising that such a low level of constituents has no effect on the IN abilities of the particles. The other three washed samples contained a greater amount of soluble ions $\left(6 \times 10^{4}-2 \times 10^{5}\right.$ soluble ions per particle), which was less than a monolayer of ions $\left(5 \times 10^{5}\right.$ soluble ions per particle, assuming that a monolayer coverage is $5 \times 10^{14}$ soluble ions $\mathrm{cm}^{-2}$ ). The unwashed MDD, ATD, and orthoclase samples all contained a greater concentration of soluble ions than their washed counterparts.

It is well known that clay minerals undergo exchange between soluble cations and hydronium ions in solution, which may then affect their surface compositions, and hence IN activity. It is difficult to assess the importance of this effect for natural samples, making it hard to claim that wet atomization or dry dispersal is the best method for particle preparation in laboratory studies. On the one hand, through the action of rain all natural samples are exposed on the ground to water prior to dispersion as an aerosol. As well, most particles are thought to pass through regions of water saturation before reaching altitudes at which cirrus clouds form (Wiacek et al., 2010). On the other hand, it is quite possible that the few trajectories that do not pass through water saturation are those that deliver the best IN to the upper troposphere. The work of Cziczo et al. (2013) indicates that the particles with the fewest soluble impurities appear to be the best IN. Thus, while each aerosol preparation method has its merits, it is difficult to claim that either dry dispersal or wet atomization is universally the most atmospherically appropriate method.

An important additional point to make, as described by Koehler et al. (2007), is that atomized multicomponent mixtures such as MDD and ATD may lose some atmospheric relevancy due to the redistribution of soluble material, if there is a lot of soluble material present. However, for the goals of our paper (i.e. to compare the ice nucleating abilities of single component minerals to multicomponent mixtures), all of the 
samples were washed prior to atomization in order to remove as much soluble material as possible before making this comparison. As a result, their soluble material that may otherwise have been redistributed on the multicomponent mixtures was removed prior to atomization.

\section{Conclusions and atmospheric implications}

This study represents the first examination of the deposition ice nucleating abilities of a wide number of mineral substances where the experimental procedure has been kept constant throughout, leading to a better understanding of the most important ice forming materials. The major findings from this work are that the feldspar minerals are the most active natural minerals studied, rivalling the anthropogenic material lead iodide, which has a good crystallographic match with ice (Schaefer, 1954; Vonnegut, 1947). Consistent with this, the MDD dust sample, which is thought to have a much lower weathered rock component than ATD, was found to be the more active dust sample. Of the three clay minerals tested, illite and montmorillonite were not as active as the feldspar minerals themselves, especially orthoclase, or the feldspar-containing dusts. In contrast, kaolinite was found to have higher activity than the other clays, closer to that of the feldspar minerals. This indicates that the efficiency of IN may be attributed to either hydrogen bonding or ionic interactions between the IN surface and water molecules. The least active materials were the metal oxides, carbonates, sulfates, sulfides, and pure metal. By working with the same experimental protocol throughout, this study isolates the ice nucleating substance itself as the determinant of the onset for nucleation, and removes factors such as temperature, particle size, ice crystal detection technique, and the definition of ice onset. Given that all the samples were wet atomized in this work, it would be interesting to determine the relative ranking using dry dispersed particles of the same size.

We note that the minerals (e.g. quartz, calcite, hematite, magnetite) lacking a surface charge are poor IN, whereas those that are good IN are able to bond strongly with hydrogen via the presence of surface hydroxyl groups (kaolinite, feldspars), or possess a net charge in their crystal lattice (illite, feldspars). The ability to participate in electrostatic interactions may then be added as a characteristic of a good IN, beyond the ability to bond simply with hydrogen (Pruppacher and Klett, 1997). Indeed, it may be for this reason that soluble salts, such as ammonium sulfate and sodium chloride, have been shown to show deposition IN abilities, provided that the temperature is below their eutectic (Abbatt et al., 2006; Wise et al., 2012).

The most striking example of this effect in this study is demonstrated by orthoclase (i.e. K-feldspar), which was identified as the most active component of both of the mineral dusts. This conclusion has now been made by this study in the deposition mode, which nicely matches the findings from the concurrent study of Atkinson et al. (2013) for the immersion mode. Together, plagioclase and orthoclase feldspars have been reported to represent $5 \%$ to $16 \%$ of African and Asian dust particles that reach the atmosphere (Shi, 2005; Jeong, 2008; Awadh, 2012). In comparison, $48 \%$ of Asian dust particles have been identified as clay aggregates (Jeong, 2008). Although the presence of feldspars in dust particles is less than that of clay minerals, their effect may still be substantial as some may be significantly more active as IN in the deposition mode. For this reason it is important that these feldspar-containing particles be further investigated in order for their effects to be appropriately incorporated into global climate models. One issue to consider is the degree to which such good IN are removed by cloud processing prior to reaching the upper troposphere, where much cirrus cloud formation occurs.

Another conclusion from this work is that many species, such as metal oxides and carbonates, are poor deposition IN. Given that many metal oxides are formed by mining and smelting activities (Aragón Piña et al., 2000; Fernández et al., 2000; Swaine, 2000; Li and Thornton, 2001; Burt et al., 2003), it seems unlikely that there is an anthropogenic effect on ice nucleation through the release of such species to the atmosphere. On the other hand, if cloud seeding were to proceed under deposition mode conditions, for example in the seeding of cirrus clouds, it appears that feldspar minerals would be a good option.

Acknowledgements. We thank G. Henderson (University of Toronto) for providing the calcite and feldspar samples, and L. Beegle (Jet Propulsion Laboratory) for the MDD samples. This work was supported by NSERC and the CSA. Constructive comments on this project came from Z. Kanji, and from D. Cziczo, who indicated that metals were being observed in ice cloud residuals

Edited by: T. Koop

\section{References}

Abbatt, J. P. D., Benz, S., Cziczo, D. J., Kanji, Z., Lohmann, U., and Möhler, O.: Solid ammonium sulfate aerosols as ice nuclei: a pathway for cirrus cloud formation, Science, 313, 1770-1773, doi:10.1126/science.1129726, 2006.

Aragón Piña, A., Torres Villaseñor, G., Monroy Ferna, M., Luszczewski Kudra, A., and Leyva Ramos, R.: Scanning electron microscope and statistical analysis of suspended heavy metal particles in San Luis Potosi, Mexico, Atmos. Environ., 34, 41034112, 2000.

Archuleta, C. M., DeMott, P. J., and Kreidenweis, S. M.: Ice nucleation by surrogates for atmospheric mineral dust and mineral dust/sulfate particles at cirrus temperatures, Atmos. Chem. Phys., 5, 2617-2634, doi:10.5194/acp-5-2617-2005, 2005.

Atkinson, J. D., Murray, B. J., Woodhouse, M. T., Whale, T. F., Baustian, K. J., Carslaw, K. S., Dobbie, S., O'Sullivan, D., and Malkin, T. L.: The importance of feldspar for ice nucleation 
by mineral dust in mixed-phase clouds., Nature, 498, 355-358, doi:10.1038/nature12278, 2013.

Awadh, S. M.: Geochemistry and mineralogical composition of the airborne particles of sand dunes and dust storms settled in Iraq and their environmental impacts, Environ. Earth Sci., 66, 22472256, doi:10.1007/s12665-011-1445-6, 2012.

Baker, M. B. and Peter, T.: Small-scale cloud processes and climate., Nature, 451, 299-300, doi:10.1038/nature06594, 2008.

Baklanov, A. M., Gorbunov, B. Z., Kakutkina, N. A., Sidorov, S. I., Silin, N. A., and Hvan, S. B.: The influence of lead iodide aerosol dispersity on its ice-forming activity, J. Aerosol Sci., 22, 9-14, doi:10.1016/0021-8502(91)90089-Z, 1991.

Barnes, W. H.: The crystal structure of ice between 0 degrees C. and -183 degrees C, P. R. Soc. London, 125, 670-693, 1929.

Bear, R. E.: Chemistry of the soil, second., Reinhold Publishing Corporation, New York., 1964.

Broadley, S. L., Murray, B. J., Herbert, R. J., Atkinson, J. D., Dobbie, S., Malkin, T. L., Condliffe, E., and Neve, L.: Immersion mode heterogeneous ice nucleation by an illite rich powder representative of atmospheric mineral dust, Atmos. Chem. Phys., 12, 287-307, doi:10.5194/acp-12-287-2012, 2012.

Burt, R., Wilson, M. A., Keck, T. J., Dougherty, B. D., Strom, D. E., and Lindahl, J. A.: Trace element speciation in selected smeltercontaminated soils in Anaconda and Deer Lodge Valley, Montana, USA, Adv. Environ. Res., 8, 51-67, doi:10.1016/S10930191(02)00140-5, 2003.

Carlson, C. G.: A Test of the Feldspar Method for the Determination of the Origin of Metamorphic Rocks, The Journal of Geology, 28, 632-642, 1920.

Colville, A. A. and Ribbe, P. H.: The crystal structure of an adularia and a refinement of the structure of orthoclase, The American Mineralogist, 53, 25-37, 1968.

Cziczo, D. J., Froyd, K. D., Hoose, C., Jensen, E. J., Diao, M., Zondlo, M. A., Smith, J. B., Twohy, C. H., and Murphy, D. M.: Clarifying the dominant sources and mechanisms of cirrus cloud formation., Science, 340, 1320-1324, doi:10.1126/science.1234145, 2013.

DeMott, P. J., Prenni, A. J., Liu, X., Kreidenweis, S. M., Petters, M. D., Twohy, C. H., Richardson, M. S., Eidhammer, T., and Rogers, D. C.: Predicting global atmospheric ice nuclei distributions and their impacts on climate., P. Natl. Aca. Sci. USA, 107, 1121711222, doi:10.1073/pnas.0910818107, 2010.

Fenter, P., Teng, H., Geissbuhler, P., Hanchar, J. M., Nagy, K. L.m and Sturchio, N. C.: Atomic-scale structure of the orthoclase (001) - water interface measured with high-resolution X-ray reflectivity, Geochimi. Cosmochim. Ac., 64, 3663-3673, 2000.

Fernández, A. J., Ternero, M., Barragán, F. J., and Jiménez, J. C.: An approach to characterization of sources of urban airborne particles through heavy metal speciation, Chemosphere - Global Change Sci., 2, 123-136, 2000.

Fitz Gerald, J. D., Parise, J. B., and Mackinnon, I.: Average structure of an An 48 plagioclase from the Hogarth Ranges, Am. Mineral., 71, 1399-1408, 1986.

Fletcher, N. H.: Size Effect in Heterogeneous Nucleation, J. Chem. Phys., 29, 572, doi:10.1063/1.1744540, 1958.

Forster, P., Venkatachalam, R., Artaxo, P., Berntsen, T., Betts, R., Fahey, D. W., Haywood, J., and Lean, J.: Changes in Atmospheric Constituents and in Radiative Forcing, in Climate Change 2007: The Physical Science Basis, edited by: S.
Solomon, D. Qin, M. Manning, C. Z, M. Marquis, K. B. Averyt, M. Tignor, and H. L. Miller, Cambridge University Press, Cambridge., 2007.

Frost, R. L.: Hydroxyl deformation in kaolins, Clays Clay Miner., 46, 280-289, 1998.

Harris, F. S., Sparks, D. C., and Layton, R. G.: Nucleation of ice on lead iodide, J. Atmos. Sci., 20, 149-152, 1963.

Hoose, C. and Möhler, O.: Heterogeneous ice nucleation on atmospheric aerosols: a review of results from laboratory experiments, Atmos. Chem. Phys., 12, 9817-9854, doi:10.5194/acp-12-98172012, 2012.

$\mathrm{Hu}$, Y., Liu, X., and Xu, Z.: Role of crystal structure in flotation separation of diaspore from kaolinite, pyrophyllite and illite, Miner Eng., 16, 219-227, doi:10.1016/S0892-6875(02)00368-0, 2003.

Isono, B. K. and Ikebe, Y.: On the ice-nucleating ability of rockforming minerals and soil particles, J. Meteorol. Soc. Jpn., 38, 213-230, 1960.

Jeong, G. Y.: Bulk and single-particle mineralogy of Asian dust and a comparison with its source soils, J. Geophys. Res., 113, D02208, doi:10.1029/2007JD008606, 2008.

Kanji, Z. A. and Abbatt, J. P. D.: Laboratory studies of ice formation via deposition mode nucleation onto mineral dust and n-hexane soot samples, J. Geophys. Res., 111, D16204, doi:10.1029/2005JD006766, 2006.

Kanji, Z. A. and Abbatt, J. P. D.: The University of Toronto Continuous Flow Diffusion Chamber (UT-CFDC): A Simple Design for Ice Nucleation Studies, Aerosol Sci. Technol., 43, 730-738, doi:10.1080/02786820902889861, 2009.

Koehler, K. A., Kreidenweis, S. M., DeMott, P. J., Petters, M. D., Prenni, A. J., and Möhler, O.: Laboratory investigations of the impact of mineral dust aerosol on cold cloud formation, Atmos. Chem. Phys., 10, 11955-11968, doi:10.5194/acp10-11955-2010, 2010.

Koehler, K. A., Kreidenweis, S. M., DeMott, P. J., Prenni, A. J., and Petters, M. D.: Potential impact of Owens (dry) Lake dust on warm and cold cloud formation, J. Geophys. Res., 112, D12210, doi:10.1029/2007JD008413, 2007.

Koop, T., Luo, B., Tsias, A., and Peter, T.: Water activity as the determinant for homogeneous ice nucleation in aqueous solutions, Nature, 406, 611-614, doi:10.1038/35020537, 2000.

Kumai, M.: Snow crystals and the identification of the nuclei in the northern United States of America, J. Meteorol., 18, 139-150, 1961.

Ladino, L. A. and Abbatt, J. P. D.: Laboratory investigation of Martian water ice cloud formation using dust aerosol simulants, J. Geophys. Res., 118, 14-25, doi:10.1029/2012JE004238, 2013.

Lau, K. M. and Wu, H. T.: Warm rain processes over tropical oceans and climate implications, Geophys. Res. Lett., 30, 2290, doi:10.1029/2003GL018567, 2003.

Li, X. and Thornton, I.: Chemical partitioning of trace and major elements in soils contaminated by mining and smelting activities, Appl. Geochem., 16, 1693-1706, doi:10.1016/S08832927(01)00065-8, 2001.

Linke, C., Möhler, O., Veres, A., Mohácsi, Á., Bozóki, Z., Szabó, G., and Schnaiter, M.: Optical properties and mineralogical composition of different Saharan mineral dust samples: a laboratory study, Atmos. Chem. Phys., 6, 3315-3323, doi:10.5194/acp-63315-2006, 2006. 
Lohmann, U. and Diehl, K.: Sensitivity Studies of the Importance of Dust Ice Nuclei for the Indirect Aerosol Effect on Stratiform Mixed-Phase Clouds, J. Atmos. Sci., 63, 968-982, 2006.

Mason, J. and Maybank, J.: Ice-nucleating properties of some natural mineral dusts, Q. J. R. Meteorol. Soc., 84, 235-241, doi:10.1002/ qj.49708436104, 1958.

Möhler, O., Field, P. R., Connolly, P., Benz, S., Saathoff, H., Schnaiter, M., Wagner, R., Cotton, R., Krämer, M., Mangold, A., and Heymsfield, A. J.: Efficiency of the deposition mode ice nucleation on mineral dust particles, Atmos. Chem. Phys., 6, 30073021, doi:10.5194/acp-6-3007-2006, 2006.

Morgan, G. M.: Technique for detecting lead particles in air, Nature, 213, 58-59, 1967.

Morgan, G. M. and Allee, P. A.: The production of potential ice nuclei by gasoline engines, J. Appl. Meteorol., 7, 241-246, 1968.

Murphy, D. M. and Koop, T.: Review of the vapour pressures of ice and supercooled water for atmospheric applications, Q. J. Roy. Meteor. Soc., 131, 1539-1565, doi:10.1256/qj.04.94, 2005.

Papike, J. J. and Cameron, M.: Crystal chemistry of silicate minerals of geophysical interest, Rev. Geophys. Space Phys., 14, 37-80, 1976.

Parungo, F. P. and Rhea, J. O.: Lead measurement in urban air as it relates to weather modification, J. Appl. Meteorol., 9, 468-475, 1970.

Peters, G. H., Abbey, W., Bearman, G. H., Mungas, G. S., Smith, J. A., Anderson, R. C., Douglas, S., and Beegle, L. W.: Mojave Mars simulant - Characterization of a new geologic Mars analog, Icarus, 197, 470-479, doi:10.1016/j.icarus.2008.05.004, 2008.

Phebus, B. D., Johnson, A. V., Mar, B., Stone, B. M., Colaprete, A., and Iraci, L. T.: Water ice nucleation characteristics of JSC Mars-1 regolith simulant under simulated Martian atmospheric conditions, J. Geophys. Res., 116, E04009, doi:10.1029/2010JE003699, 2011.

Phillips, M. W., Colville, A. A., and Ribbe, P. H.: The crystal structures of two oligoclases: A comparison with low and high albite, Zeitschrift für Kristallographie, 133, 43-65, 1971.

Pruppacher, H. R. and Klett, J. D.: Microphysics of clouds and precipitation, 18th edn., Kluwer Academic Publishers, Dordrecht., 1997.

Ramanathan, V., Crutzen, P. J., Kiehl, J. T., and Rosenfeld, D.: Aerosols, climate, and the hydrological cycle., Science (New York, N.Y.), 294, 2119-24, doi:10.1126/science.1064034, 2001.

Reischel, M. T.: Ice nuclei from reactions involving lead, ammonia, and iodine, Atmos. Environ., 9, 955-958, 1975.

Roberts, B. P. and Hallett, J.: A laboratory study of the ice nucleating properties of some mineral particulates, Q. J. R. Meteorol. Soc., 94, 25-34, doi:10.1002/qj.49709439904, 1967.

Rosinski, J., Langer, G., Nagamoto, C. T., Kerrigan, T. C., and Prodi, F.: Natural Ice-Forming Nuclei in Severe Convective Storms, J. Atmosp. Sci., 28, 391-401, 1971.

Rosinski, J. and Nagamoto, C. T.: Contact nucleation of ice by natural aerosol particles, J. Aerosol. Sci., 7, 1-4, 1976a.

Rosinski, J. and Nagamoto, C. T.: Large aerosol particles as freezing nuclei, J. Aerosol. Sci., 7, 479-483, 1976b.

Rosinski, J., Nagamoto, C. T., Kerrigan T, C., and Langer, G.: Reply, J. Atmos. Sci., 31, 1459-1464, 1974.
Salam, A., Lohmann, U., Crenna, B., Lesins, G., Klages, P., Rogers, D., Irani, R., MacGillivray, A., and Coffin, M.: Ice Nucleation Studies of Mineral Dust Particles with a New Continuous Flow Diffusion Chamber, Aerosol Sci. Technol., 40, 134-143, doi:10.1080/02786820500444853, 2006.

Schaefer, V. J.: Silver and lead iodide as ice-crystal nuclei, J. Meteorol., 11, 417-419, 1954.

Schaefer, V. J.: Ice nuclei from automobile exhaust and iodine vapor, Science, 154, 1555-1557, doi:10.1126/science.154.3756.1555-a, 1966.

Schlegel, M. L., Nagy, K. L., Fenter, P., and Sturchio, N. C.: Structures of quatz (1010)- and (1011)-water interfaces determined by $\mathrm{X}$-ray reflectivity and atomic force microscopy of natural growth surfaces, Geochim. Cosmochim. Ac., 66, 3037-3054, 2002.

Shi, Z.: Microscopy and mineralogy of airborne particles collected during severe dust storm episodes in Beijing, China, J. Geophys. Res., 110, D01303, doi:10.1029/2004JD005073, 2005.

Swaine, D. J.: Why trace elements are important, Fuel Process. Technol., 65, 21-33, doi:10.1016/S0378-3820(99)00073-9, 2000.

Swartzen-Allen, S. L. and Matijevic, E.: Surface and colloid chemistry of clays, Chem. Rev., 74, 385-400, doi:10.1021/cr60289a004, 1974.

Vali, G.: Nucleation terminology, J. Aerosol Sci., 16, 575-576, 1985.

Vonnegut, B.: The Nucleation of Ice Formation by Silver Iodide, J. Appl. Phys., 18, 593, doi:10.1063/1.1697813, 1947.

Welti, A., Lüönd, F., Stetzer, O., and Lohmann, U.: Influence of particle size on the ice nucleating ability of mineral dusts, Atmos. Chem. Phys., 9, 6705-6715, doi:10.5194/acp-9-6705-2009, 2009.

Wenk, H., Joswig, W., Tagai, T., Korekawa, M., and Smith, B. K.: The average structure of An 62-66 labradorite, Am. Mineral., 65, 81-95, 1980.

Wheeler, M. J. and Bertram, A. K.: Deposition nucleation on mineral dust particles: a case against classical nucleation theory with the assumption of a single contact angle, Atmos. Chem. Phys., 12, 1189-1201, doi:10.5194/acp-12-1189-2012, 2012.

Wiacek, A., Peter, T., and Lohmann, U.: The potential influence of Asian and African mineral dust on ice, mixed-phase and liquid water clouds, Atmos. Chem. Phys., 10, 8649-8667, doi:10.5194/acp-10-8649-2010, 2010.

Wise, M. E., Baustian, K. J., Koop, T., Freedman, M. A., Jensen, E. J., and Tolbert, M. A.: Depositional ice nucleation onto crystalline hydrated $\mathrm{NaCl}$ particles: a new mechanism for ice formation in the troposphere, Atmos. Chem. Phys., 12, 1121-1134, doi:10.5194/acp-12-1121-2012, 2012.

Zimmermann, F., Weinbruch, S., Schütz, L., Hofmann, H., Ebert, M., Kandler, K., and Worringen, A.: Ice nucleation properties of the most abundant mineral dust phases, J. Geophys. Res., 113, D23204, doi:10.1029/2008JD010655, 2008.

Zuberi, B., Bertram, A. K., Cassa, C. A., Molina, L. T., and Molina, M. J.: Heterogeneous nucleation of ice in $\left(\mathrm{NH}_{4}\right)_{2} \mathrm{SO}_{4}-\mathrm{H}_{2} \mathrm{O}$ particles with mineral dust immersions, Geophys. Res. Lett., 29, 142-1-142-4, 2002. 